\title{
Habilidades, características pessoais, interesses e estilos de aprendizagem de adolescentes talentosos
}

\author{
Jane Farias Chagas ${ }^{1}$ - Secretaria Extraordinária de Educação Integral do Distrito Federal, Brasília, Brasil \\ Denise de Souza Fleith - Universidade de Brasilia, Brasilia, Brasil
}

\begin{abstract}
Resumo
O objetivo deste estudo foi descrever habilidades, características pessoais, interesses e estilos de aprendizagem de adolescentes talentosos. Participaram da pesquisa 42 alunos que frequentavam um programa de atendimento ao superdotado na região centro-oeste. $\mathrm{O}$ instrumento utilizado foi uma lista de habilidades, interesses, preferências, características e estilos de aprendizagem, elaborada para o estudo. Os adolescentes informaram apresentar um melhor desempenho associado às habilidades intrapessoal (77\%), interpessoal (68\%) e linguístico-verbal (60\%). Os resultados revelaram que os participantes percebiam-se como persistentes $(84,2 \%)$, exigentes consigo mesmos (76,3\%), possuidores de valores morais sólidos $(76,3 \%)$ e criativos $(71,1 \%)$. Entre interesses e aspectos motivacionais elencados pelos adolescentes, destacaram-se: ter muitas idéias sobre muitas coisas $(89,5 \%)$, ir até o fim quando buscavam atingir um objetivo (86,8\%), gostar de tirar boas notas na escola $(81,6 \%)$, gostar de experimentar coisas novas $(78,9 \%)$. Os participantes informaram que aprendiam com mais facilidade por meio da leitura e discussão de idéias $(71,1 \%)$.

Palavras-chave: Adolescentes, Talento, Características do estudante, Interesses.
\end{abstract}

\section{Abilities, personal characteristics, interests and learning styles of talented adolescents}

\begin{abstract}
The purpose of this study was to describe abilities, personal characteristics, interests and learning styles of talented adolescents. Forty-two students who attended a program for the gifted in central-west region participated in the research. The instrument used was a list of abilities, interests, preferences, characteristics and learning styles, designed for the study. Adolescents have reported better performance associated with intrapersonal (77\%), interpersonal $(68 \%)$ and linguistic-verbal $(60 \%)$ abilities. The results revealed that participants perceived themselves as persistent (84.2\%), demanding with themselves (76.3\%), owners of solid moral values $(76.3 \%)$ and creative $(71.1 \%)$. Among interests and motivational aspects listed by the adolescents, it could be highlighted: having many ideas about many things $(89.5 \%)$, going all the way when seeking to achieve a goal $(86.8 \%)$, liking getting good grades in school (81.6\%), liking trying new things (78.9\%). Participants said they learned more easily through reading and discussion of ideas $(71.1 \%)$.

Keywords: Adolescents, Talent, Student characteristics, Interests.
\end{abstract}

Vários autores reconhecem o avanço histórico na direção de atender às necessidades específicas do adolescente no Brasil a partir da promulgação do Estatuto da Criança e do Adolescente em 1990. No entanto, há problemas e lacunas referentes à saúde e educação dos adolescentes que precisam de urgente atenção e intervenção especializada (Bianculli, 1997; Hutz, 2002). Entre eles podemos destacar a defasagem idade série, a evasão escolar e a vitimização e alto número de óbitos nessa fase por causa da violência, de suicídio, homicídio e acidentes de trânsito (UNICEF, 2002a; 2002b). Esse quadro desolador em uma etapa altamente criativa e produtiva da vida "não só pune o indivíduo e o grupo que lhe é próximo, mas também priva toda

\footnotetext{
${ }^{1}$ Este artigo é derivado da Tese de Doutorado da primeira autora, orientada pela segunda.

Endereço para correspondência:

Quadra 5 - Conjunto F - Casa 53 - 73030056 - Sobradinho-DF.

E-mail: janefcha@gmail.com, fleith@unb.br
}

a coletividade de seu potencial intelectual e econômico" (Costa, Ludemir \& Avelar, 2007, p. 1194).

Diante desse panorama desafiador, podemos inferir a situação de vulnerabilidade a que está submetido o adolescente talentoso, uma vez que sentimentos de isolamento, solidão e confusão, característicos da adolescência, podem ser acentuados em razão do seu funcionamento intelectual e socioemocional peculiar. Em geral, crianças e adolescentes talentosos tendem a demonstrar elevada intensidade e sensibilidade emocional e intelectual. Essas características percebidas na infância podem perdurar por toda a vida, dependendo da trajetória, da configuração social e do tipo de talento (Edmunds \& Edmunds, 2005; Fortes-Lustosa, 2007; Ourofino \& Guimarães, 2007; Sabatella, 2008).

Entre as características intelectuais típicas de crianças talentosas que são exacerbadas durante a adolescência e que impactam a interação com os pares e a formação da identidade, destacamos aquelas citadas por Sabatella (2008): precocidade 
no desenvolvimento físico, cognitivo e social, altos níveis de atenção e concentração, memória de reconhecimento aguçada, preferência por novidades, proficiência verbal, senso de humor incomum e sofisticado. Do ponto de vista neurológico, essas características intelectuais são associadas à alta eficiência do funcionamento e às diferenças qualitativas da organização cerebral (Sabatella, 2008; Winner, 1998).

Quanto ao ajustamento socioemocional de adolescentes talentosos, as pesquisas apontam resultados controversos. De um lado, revelam que esses adolescentes são mais ajustados quando comparados com seus pares não talentosos (Neihart, 1999; Winner, 1998). Esses resultados indicam que a capacidade intelectual pode funcionar como fator de proteção, proporcionando aos jovens talentosos a possibilidade de apresentarem menor nível de depressão, grande senso de adequação, níveis superiores de atenção, maior maturidade intelectual, habilidades avançadas de resolução de problemas, atitude mais positiva ante as adversidades ambientais, desenvolvimento social precoce, autoestima elevada e autoconceito mais positivo (Richards, Encel \& Shute, 2003). Os adolescentes talentosos, em geral, demonstram um desenvolvimento privilegiado com relação a vários aspectos morais: julgamento, sensibilidade, atitude, imaginação e motivação (Fortes-Lustosa, 2004; 2007).

No entanto, há autores que sugerem que jovens talentosos, especialmente aqueles com habilidades extremas, apresentam maior vulnerabilidade a problemas emocionais e sociais e maiores riscos para a depressão, ansiedade e de suicídio (Grobman, 2006; Jackson \& Peterson, 2003; Neihart, 2006; Schultz \& Deslile, 2003).

É importante ressaltar que os adolescentes talentosos, como os demais superdotados, não constituem um grupo homogêneo. Portanto, o desenvolvimento de suas habilidades, a qualidade de vida e o seu sucesso ou a autorrealização dependem de um conjunto complexo de variáveis individuais e ambientais. Esses fatores compõem uma teia específica ou fluxo de influências significativas entre o processo-pessoa-contextotempo. As competências e características pessoais estimuladas por demandas sócio-históricoculturais vão tecendo a trajetória única de cada indivíduo talentoso ao longo do seu curso de vida (Chagas, 2007; 2008; Sabatella, 2008). Também é igualmente relevante mencionar que, apesar deste estudo apresentar um recorte e ênfase na adolescência, o desenvolvimento do talento é contínuo, dinâmico e multifacetado.

O objetivo desta pesquisa foi descrever as características individuais de adolescentes talentosos. Para atender aos objetivos, adotamos a definição baseada em modelo multifatorial desenvolvida por Renzulli e Reis (1997), descrita no Modelo dos Três Anéis. O conceito adotado envolve a interação dinâmica entre três fatores interligados: habilidade acima da média, criatividade e envolvimento com a tarefa. A habilidade acima da média pode ser geral ou específica. As habilidades gerais consistem no engajamento de processos de pensamento abstrato, na capacidade de processar informações e integrar experiências que resultem em respostas adaptativas ou adequadas a novas situações e problemas. Essas habilidades são relacionadas à memória, à fluência verbal, ao raciocínio lógico e numérico e às relações espaciais. As habilidades específicas são relacionadas à capacidade de adquirir conhecimentos e dominar técnicas e estratégias aplicadas a um domínio em particular, como música, literatura, física, dança e astronomia. Ao contrário das habilidades gerais, as habilidades específicas não são facilmente medidas em testes psicométricos.

O envolvimento com a tarefa é o anel relacionado aos fatores motivacionais, descritos em termos de altos níveis de perseverança, energia, concentração e dedicação investidos na execução de um projeto, problema ou área de performance em particular. A criatividade é o fator que reúne características do pensamento criativo (fluência, flexibilidade e originalidade), traços de personalidade (abertura a novas experiências, sensibilidade, coragem de correr riscos e curiosidade) e características de produção criativa (inovação, abundância ou riqueza de detalhes).

Para Renzulli e Reis (1997), há dois tipos de superdotação: uma acadêmica ou escolar e a outra criativo-produtiva. A superdotação acadêmica, como o próprio nome informa, está relacionada às habilidades acadêmicas, como aprender rapidamente e tirar boas notas. A superdotação criativo-produtiva diz respeito às atividades humanas nas quais o desenvolvimento de produtos originais é valorizado (Alencar, 2007). Para esses autores, os tipos de superdotação são igualmente importantes e estão associados a determinadas características e habilidades individuais e às demandas socioculturais do ambiente em que o indivíduo está inserido (Chagas, 2008). 
Tendo em vista atender aos objetivos de nosso estudo, formulamos a seguinte pergunta: Quais são as habilidades, as características pessoais, as preferências, os interesses, os aspectos motivacionais e os estilos de aprendizagem de adolescentes talentosos?

\section{Método}

Nesta pesquisa utilizamos uma metodologia descritiva, considerada uma fonte valiosa de levantamento de evidências e formulação de hipóteses por apresentar informação detalhada sobre incidência ou prevalência de eventos e características com relação à população estudada (Günther, 2006).

\section{Participantes}

Participaram da pesquisa 42 adolescentes com idade entre 12 e 18 anos $(M=13,8$ anos, $\mathrm{DP}=1,82)$. Desses, 29 eram do sexo masculino e 13 do sexo feminino. Quanto à escolaridade, 27 adolescentes frequentavam o ensino fundamental, 12 estavam no ensino médio, 1 havia completado o ensino médio e dois não responderam a essa questão. Com relação ao desempenho escolar, 27 informaram que tinham notas escolares acima da média $(65,9 \%), 12$, que tinham notas na média $(28,6 \%), 2$, que tinham notas abaixo da média $(4,8$ $\%$ e um aluno não informou o desempenho escolar. Destes, 32 estudavam em escolas públicas $(76,2 \%), 6$ estudavam em escolas particulares $(14,3 \%)$ e 4 não responderam $(9,5 \%)$. Todos os adolescentes participavam do programa de atendimento ao aluno superdotado da Secretaria de Estado de Educação do Distrito Federal e já haviam sido identificados como superdotados.

Com relação à área de talento, 20 adolescentes eram atendidos em uma área artística (música, artes plásticas/desenho, artes cênicas), 18 alunos eram atendidos em uma área acadêmica (português/literatura, matemática, ciências, geografia, informática/robótica), 2 alunos tinham talento em ambas as áreas: artística e acadêmica e 2 alunos não indicaram as áreas de talento. Os adolescentes ocupavam as seguintes posições de nascimento ${ }^{2}$ : filho único $(n=5)$, primogênito $(n=11)$, segundo filho $(n=11)$, terceiro filho $(n=2)$, quarto filho $(n=3)$, filho mais novo $(n=8)$, não informaram $(n=2)$. No entanto, essas posições eram diferenciadas quando se tratava da posição

2 Posição de nascimento - diz respeito à ordem de nascimento do indivíduo na família. funcional na família33. Com relação à posição funcional, $40,5 \%$ deles ocupavam a posição de filhos únicos $(\mathrm{n}=17), 14,3 \%$ eram segundo filhos $(n=6), \quad 14,3 \%$ eram primogênitos $(n=6), 14,3 \%$ eram caçulas $(n=6)$ e os demais $16,6 \%$ ocupavam outra posição $(n=5)$ ou não responderam $(n=2)$.

\section{Instrumentos}

Lista de Habilidades, Interesses, Preferências, Características e Estilos de Aprendizagem - LHIPCEA. Essa lista foi elaborada, pela primeira autora, com base na Teoria das Inteligências Múltiplas (Chen, Isberg \& Krechevsky, 2001; Gardner, 2001), na Teoria de Dabrowski (Fortes-Lustosa, 2004), na Escala para Avaliação das Características Comportamentais de Alunos com Habilidades Superiores, revisada por Renzulli e cols. (2000), e no Inventário de Estilos de Aprendizagem desenvolvido por Renzulli e Smith (2001). A LHIPCEA é composta por cinco categorias: (1) habilidades, (2) preferências, interesses e aspectos motivacionais, (3) características pessoais, (4) relações interpessoais e acadêmicas e (5) estilos de aprendizagem.

As habilidades foram dispostas de acordo com o tipo de inteligência definida por Gardner (2001) e Chen, Isberg e Krechevsky (2001): linguística-verbal (23 itens), lógico-matemática (21 itens), visoespacial (18 itens), musical (15 itens), cinestésica, subdividida em corporal-cinestésica (13 itens) e mecânica-construção (18 itens), interpessoal (17 itens), intrapessoal (11 itens) e naturalista (18 itens). Os itens dessas oito subcategorias foram assinalados com base em escala com quatro níveis de respostas: faço bem, faria bem se soubesse, não faço bem e não faço.

Preferências, interesses e aspectos motivacionais, bem como características pessoais, foram compostos, respectivamente, por 47 e 37 itens (exemplos: gosto de correr riscos; confio em minhas habilidades; sou perfeccionista), assinalados quanto à ocorrência: sim, não e às vezes. As categorias relações interpessoais e acadêmicas e os estilos de aprendizagem tinham 19 e 27 itens, respectivamente, e foram assinaladas com relação à ocorrência ou não de cada item (exemplos: sou aceito e integrado na minha família; já recebi prêmios em concursos; você aprende melhor: lendo, trabalhando e grupo).

É importante ressaltar que este instrumento, além de ser examinado por

\footnotetext{
${ }^{3}$ Posição funcional - diz respeito à posição que o indivíduo ocupa na família, que pode ser diferente da ordem de nascimento devido à morte, adoção ou saída de casa de um irmão.
} 
especialistas da área de superdotação (professores pesquisadores e alunos de pós-graduação), foi objeto de estudo piloto com o intuito de ajustar suas questões, envolvendo a participação de dois adolescentes dentro da faixa etária estabelecida na pesquisa.

\section{Procedimentos}

Inicialmente foi entregue a Carta de Apresentação e assinado o Termo de Consentimento Livre e Esclarecido pelos adolescentes e seus pais. A Lista de Habilidades, Interesses, Preferências, Características e Estilos de Aprendizagem - LHIPCEA foi aplicada a cada aluno individualmente, pelos professores ou psicólogos do Programa de Atendimento ao Aluno Superdotado da Secretaria de Estado de Educação do Distrito Federal.

\section{Análise de dados}

Os dados foram analisados por procedimentos estatísticos descritivos e o programa SPSS foi utilizado como ferramenta estatística. Os adolescentes foram subdivididos em grupos de análise de acordo com a sua área de atendimento: adolescentes com talento acadêmico $(n=20)$, adolescentes com talento artístico $(n=18)$ e adolescentes com duplo talento - área acadêmica e artística $(n=2)$.

\section{Resultados}

\section{Habilidades}

Os adolescentes talentosos $(n=40)$ informaram apresentar um melhor desempenho associado às habilidades intrapessoal (77\%), interpessoal $(68 \%)$ e linguístico-verbal $(60 \%)$. As expectativas de bom desempenho na percepção de $34 \%$ dos adolescentes estavam direcionadas às habilidades musicais. As habilidades associadas à inteligência naturalista foram mencionadas por $28 \%$ dos adolescentes como estando entre aquelas que eles não possuíam qualquer desempenho.

Quando comparados entre si, os adolescentes apresentaram percepção diferenciada nos quatro itens da escala: faço bem, faria bem se soubesse, não faço bem e não faço. Os adolescentes com talento acadêmico assinalaram um melhor desempenho nas áreas intrapessoal $(83 \%)$, interpessoal (75\%), linguístico-verbal $(68 \%)$ e lógico-matemática (54\%). Os adolescentes com talento artístico relataram melhor desempenho nas áreas: interpessoal (60\%), intrapessoal $(56 \%)$ e linguístico-verbal. Já os adolescentes com duplo talento informaram melhor desempenho nas áreas: musical (92\%), interpessoal (91\%) e intrapessoal (82\%).

Quanto às expectativas de bom desempenho, aproximadamente $1 / 4$ dos adolescentes com talento acadêmico vislumbravam essa possibilidade com relação às habilidades musicais $(26 \%)$, visoespaciais $(26 \%)$ e lógicomatemáticas $(24 \%)$. Os adolescentes com talento artístico informaram a área de mecânicoconstrução (25\%), seguida da linguístico-verbal $(22 \%)$ e visoespacial $(21 \%)$. Os adolescentes com duplo talento tinham expectativas maiores com relação às habilidades na área naturalista $(17 \%)$ e de mecânico-construção (17\%).

A performance inferior (não faço bem) foi vinculada pelos adolescentes com talento acadêmico às habilidades relacionadas à área de mecânica e construção (15\%), enquanto os com talento artístico informaram a área lógicomatemática $(24 \%)$. Os alunos com duplo talento referiram menor desempenho nas habilidades corporal-cinestésicas (24\%).

As habilidades pouco mencionadas por uma maior percentagem de adolescentes com talento acadêmico foram aquelas associadas às áreas musical $(32 \%)$, naturalista $(31 \%)$ e corporalcinestésica $(29 \%)$. No mesmo sentido, os adolescentes com talento artístico assinalaram as habilidades ligadas às áreas naturalista (28\%), visoespacial $(23 \%)$ e musical $(23 \%)$, enquanto os adolescentes com duplo talento apontaram as áreas lógico-matemática (14\%) e visoespacial $(14 \%)$.

\section{Características pessoais}

Com relação às características pessoais contidas na Lista de Habilidades, Interesses, Preferências e Estilos de Aprendizagem, os resultados revelaram que mais de $70 \%$ dos adolescentes talentosos percebiam-se como persistentes $(84,2 \%)$, exigentes consigo mesmos $(76,3 \%)$, possuidores de valores morais sólidos $(76,3 \%)$ e criativos $(71,1 \%)$. Quase metade desses alunos declarou que não era sensível a cheiros e gostos e que não ficava irritado, emocionado ou chorava facilmente $(47,4 \%)$. O perfeccionismo e a indecisão foram apontados como características sazonais (que ocorrem às vezes) por $44,7 \%$ dos adolescentes.

As características pessoais que se destacaram na percepção de adolescentes com talento artístico foram a criatividade $(75 \%)$, a ética nas ações $(75 \%)$, os valores morais sólidos $(70 \%)$, 
o interesse por muitas coisas ao mesmo tempo (65\%), a realização intensa de atividades de que gostavam $(65 \%)$, a sensibilidade a certos tipos de toque $(60 \%)$, a preferência por dormir mais de $8 \mathrm{~h}$ por dia $(60 \%)$ e a sensibilidade a certos tipos de iluminação $(45 \%)$. Por outro lado, uma porcentagem maior de adolescentes com talento na área acadêmica se percebiam como emotivos (chorar e ficar emocionado com facilidade) $(93,8 \%)$, organizados e disciplinados $(93,8 \%)$, extrovertidos $(87,5 \%)$, persistentes $(87,5 \%)$, idealistas $(68,8 \%)$ e perfeccionistas $(50 \%)$. A totalidade dos adolescentes com duplo talento e a maioria daqueles com talento acadêmico não se consideravam conformistas e não aceitavam as coisas como elas são. A porcentagem de adolescentes desses dois grupos que assinalaram que eram indecisos, irritadiços, agitados e inquietos era maior quando comparada à dos adolescentes com talento artístico.

\section{Preferências, interesses e aspectos motivacionais}

Entre as preferências, interesses e aspectos motivacionais com os quais os adolescentes mais se identificaram, estavam: ter muitas ideias sobre muitas coisas $(89,5 \%)$, ir até o fim quando buscavam atingir um objetivo $(86,8 \%)$, gostar de tirar boas notas na escola $(81,6 \%)$, gostar de experimentar coisas novas $(78,9)$, perder a noção de tempo quando trabalha com coisas do interesse $(78,9 \%)$, defender rigidamente os pontos de vista $(73,7 \%)$. As categorias que se seguem correspondem à preferência de $71,1 \%$ dos adolescentes: preferir situações onde possa tomar iniciativa e conduzir o trabalho, valorizar a fantasia e a imaginação, gostar de desafios, usar a imaginação para resolver problemas e ter medo de errar. $\mathrm{O}$ que os adolescentes menos apreciavam era seguir rotinas e ter que fazer as coisas sempre do mesmo jeito $(36,8 \%)$ e colecionar coisas $(31,6 \%)$.

Ainda com relação às preferências, interesses e aspectos motivacionais, 55\% dos adolescentes talentosos declararam possuir muitos interesses. Entre os interesses indicados pelos adolescentes no item "outros" e que não estavam relacionados na LHIPCEA, foram citadas as atividades associadas ao talento e às disciplinas escolares: artes $(\mathrm{f}=14)$, estudo e leitura $(\mathrm{f}=8)$, história $(\mathrm{f}=6)$, geografia $(\mathrm{f}=6)$, ciências $(\mathrm{f}=6)$, biologia $(f=6)$, esportes $(f=5)$, arquitetura $(f=5)$, engenharia $(\mathrm{f}=5)$ e maquetes $(\mathrm{f}=5)$.

A maioria dos adolescentes com talento artístico assinalou ir até o fim quando buscam atingir um objetivo (95\%), gostar de experimentar coisas novas $(85 \%)$, defender rigidamente seus pontos de vista $(80 \%)$ e confiar em sua intuição $(75 \%)$. Os adolescentes da área acadêmica assinalaram ter muitas ideias sobre muitas coisas $(93,8 \%)$, gostar de ser o centro das atenções $(62,5 \%)$, gastar mais tempo com coisas de seu interesse $(62,5 \%)$, gostar de liderar projetos e grupos $(62,5 \%)$, preferir tomar a iniciativa $(62,5 \%)$, gostar de ler sobre vários assuntos $(56,2 \%)$, ter menos dificuldade em estabelecer e obedecer a limites $(56,3 \%)$ e não gostar de rotinas e de fazer as coisas sempre do mesmo jeito $(43,7 \%)$. Apenas $18,8 \%$ desses adolescentes preferiam continuar trabalhando em projetos que não estavam dando certo, demonstrando com isso o seu nível de comprometimento com a tarefa e persistência. Entre os alunos com duplo talento, o que menos preferiam era rotina, tomar iniciativa e se envolver com uma coisa de cada vez.

\section{Relações interpessoais e acadêmicas}

A respeito das relações interpessoais e acadêmicas, os resultados demonstraram que quase a totalidade dos adolescentes informou que se considerava aceita e integrada em todos os microssistemas onde estavam inseridos: família $(97,4 \%)$, escola $(97,4 \%)$, sala de recursos $(100 \%)$, comunidade $(94,7 \%)$, igreja e clube $(89,5 \%)$. No entanto, $55 \%$ dos adolescentes com talento artístico, 43,6\% dos que tinham talento acadêmico e 1 aluno com duplo talento informaram ter recebido algum tipo de apelido pejorativo por causa do seu talento. Apesar de a maioria dos adolescentes ter relatado não ter sofrido agressão verbal $(81,6 \%)$ ou física $(89,5 \%)$ por causa de seu talento, entre os adolescentes com talento artístico essa porcentagem pode ser considerada alta. Quase um terço dos adolescentes com talento artístico declarou se sentir constrangido, rejeitado ou discriminado por causa do seu talento (30\%); $20 \%$ assinalou que sofreu algum tipo de agressão verbal e $15 \%$ que foram vítimas de agressão física $(15 \%)$. Outro dado que chama atenção é que quase metade dos adolescentes com talento acadêmico informou ter se envolvido em algum tipo de briga $(43,8 \%)$.

Entre os adolescentes em geral, 89,5\% informaram tirar boas notas na escola, $80 \%$ tiveram um professor ou mentor que os influenciou de forma positiva e 55,3\% receberam algum tipo de prêmio pela participação em concursos. Com relação às disciplinas em que se destacavam foram assinaladas: história/geografia $(\mathrm{n}=16)$, todas $(\mathrm{n}=10)$, matemática $(\mathrm{n}=9)$, 
português $(n=7)$, artes $(n=4)$ e ciências $(n=3)$. Outras disciplinas indicadas com apenas uma ocorrência foram: física, biologia e química. Dois adolescentes assinalaram que não tiravam boas notas nas disciplinas escolares e três não responderam à questão.

\section{Estilos de aprendizagem}

Os adolescentes, em geral, informaram que aprendiam com mais facilidade por meio da leitura $(71,1 \%)$, discutindo suas idéias $(71,1 \%)$, conversando com outras pessoas $(65,5 \%)$, observando como as coisas são realizadas $(63,2 \%)$ e respondendo a perguntas $(60,5 \%)$. As atividades que menos apreciavam eram planejar passos ou atividades $(28,9 \%)$, elaborar relatórios $(28,9 \%)$, estudar biografias $(26,3 \%)$ e dramatizar $(21,1 \%)$.

Os adolescentes com talento artístico tinham preferência pelo trabalho em grupo (75\%), pela leitura $(70 \%)$ e por discutir ideias com outras pessoas (65\%). Um quarto desses adolescentes assinalou que as atividades que menos favoreciam o seu aprendizado eram o estudo de biografias, trabalho com movimento, dramatização e estabelecimento de relações. Entre os adolescentes com talento acadêmico havia uma primazia pela leitura $(81,3 \%)$, discussão de ideias $(81,3 \%)$ e a conversa com outras pessoas $(81,3 \%)$. Entre as atividades que menos apreciavam estava a dramatização $(12,5 \%)$ e a elaboração de relatórios $(18,8 \%)$. Nenhum dos dois alunos com duplo talento tinha preferência pela elaboração de relatórios.

Ainda com relação aos estilos de aprendizagem, 60,5\% dos adolescentes relataram aprender trabalhando em grupo ou individualmente. Além das atividades contidas na LHIPCE $A$, três adolescentes acrescentaram: pesquisar, pensar enquanto tomam banho e estudar ouvindo música.

\section{Discussão}

Com relação às características individuais, ficou demonstrado que os adolescentes talentosos diferiam entre si em função do tipo de talento que possuíam. Entre adolescentes com talento acadêmico e artístico houve diferenças nas performances informadas em várias habilidades. Os adolescentes com talento acadêmico, por exemplo, percebiam suas habilidades na área intrapessoal, lógico-matemática e mecânico-construção de maneira mais positiva quando comparados aos adolescentes com talento artístico. Por outro lado, os adolescentes com talento artístico declararam ser mais criativos, ter maior sensibilidade ao toque e maior intensidade na realização das tarefas de que gostam.

Com base nesses resultados, podemos inferir que um conjunto de características, habilidades e interesses seja mais comum a determinado subgrupo de adolescentes com talento em campos específicos do que aos adolescentes talentosos em termos gerais. Csikszentmihalyi, Rathunde e Walen (1993) também encontraram diferenças entre as habilidades e características individuais de adolescentes talentosos associadas a diversos tipos de talento.

Apesar das diferenças observadas, os adolescentes, em geral, tinham uma percepção bastante positiva de suas habilidades intra e interpessoais. Esses jovens informaram ser éticos em suas ações e ter valores morais sólidos. Essas características pessoais, no entanto, parecem estar sujeitas às experiências e condições contextuais e não somente à intencionalidade desses jovens. Nesse sentido, Fortes-Lustosa (2004) observa que alguns aspectos podem contribuir para o desenvolvimento peculiar de sentimentos e valores morais e um nível maior de envolvimento dos adolescentes talentosos com o seu próprio desenvolvimento moral: configuração subjetiva, habilidades cognitivas e criativas mais elevadas, metacognição, consciência do seu próprio potencial e orientação para o futuro.

Ainda considerando as habilidades intra e interpessoais e os aspectos afetivos e sociais, é preciso ressaltar que quase $1 / 3$ dos adolescentes com talento artístico e mais de $40 \%$ daqueles com talento acadêmico informaram envolvimento em brigas. Aproximadamente a metade dos adolescentes da pesquisa recebeu algum apelido pejorativo, e entre estes, quase $20 \%$ dos adolescentes com talento artístico e acadêmico sofreram algum tipo de agressão verbal e física. Esses dados nos alertam quanto à questão do bullying ou assédio moral, muitas vezes associados, na literatura e na mídia, aos indivíduos que apresentam habilidades superiores (Peterson \& Ray, 2006).

O bullying é uma ação ameaçadora, preconceituosa e agressiva. Alguns aspectos do ajustamento emocional de indivíduos talentosos, como: depressão, ideação suicida, baixa autoestima e dificuldades nas relações sociais, especialmente relacionados a jovens com habilidades extremas (Neihart, 2002; Schuler, 
2002), podem estar vinculados aos efeitos do bullying. É possível que esses resultados sejam intensificados entre adolescentes talentosos em virtude de características afetivas como hipersensibilidade, senso de justiça, perfeccionismo e introversão (Peterson \& Ray, 2006). O estudo de Peterson e Ray demonstrou que nem sempre esses eventos são provocados pelos talentosos e que, muitas vezes, trata-se de uma forma de reação ao bullying. No entanto, independentemente da explicação que os resultados do nosso estudo possam ensejar, é notório que esses dados merecem atenção especial por parte da escola e da família, devendo, ainda, ser objeto de pesquisas futuras.

As características afetivas e motivacionais dos adolescentes talentosos, reveladas neste estudo, são amplamente citadas na literatura associadas aos indivíduos talentosos e criativos (Chagas, 2007; Sabatella, 2008; Winner, 1998). Entre os atributos encontrados destacamos: persistência, determinação, nível de exigência mais elevado consigo mesmo, criatividade, perfeccionismo, defesa mais rígida de pontos de vista, envolvimento intenso com a área de interesse, gosto por experimentar coisas novas, iniciativa, preferência por desafios, valorização da imaginação e fantasia, atitude positiva frente ao erro e bom humor.

O conjunto de resultados sobre as características individuais dos adolescentes de nosso estudo revela que muitos desses atributos estão em consonância com a literatura sobre indivíduos resilientes. Entre os traços convergentes destacamos aqueles apontados por Wolin e Wolin (citados em Kotliarenco, Cáceres \& Fontecilla, 1997) e Molina-Loza (2003): (a) introspecção, associada à metacognição, (b) independência, entendida como a capacidade de manter distância emocional, (c) habilidade para relacionar-se, estabelecendo laços íntimos e satisfatórios com outras pessoas (d) iniciativa no sentido de exercer controle sobre os problemas, (e) humor, definido como inclinação para encontrar graça em meio à tragédia, (f) criatividade, competência exercida na direção de criar ordem, beleza e finalidade em meio ao caos e (g) moralidade, capacidade de comprometer-se com valores e discriminar entre o bem e o mal. Os mesmos autores somam a essas características: ausência de déficit orgânico, temperamento fácil, autonomia, lócus de controle interno, motivação intrínseca, alta autoestima, maior coeficiente intelectual, amplo leque de interesses e habilidades de resolução de problemas.

A resiliência está intimamente ligada à capacidade de enfretamento e adaptação frente às situações adversas. É multideterminada e um produto da interação de forças que atuam num contexto ecossistêmico de desenvolvimento (Kotliarenco, Cáceres \& Fontecilla, 1997). É importante ressaltar que as características individuais não concorrem isoladamente para os comportamentos ou traços resilientes. Esses atributos estão associados a variáveis sóciohistórico-culturais. De acordo com Waller (2001), alguns fatores ambientais favorecem a manutenção e o desenvolvimento $\mathrm{da}$ resiliência. $\mathrm{Na}$ comunidade é salientada a necessidade de existência de recursos adequados para a saúde e nutrição, senso de comunidade, suporte entre amigos e vizinhos, ampliada rede de apoio social formal e informal e oportunidade para que os jovens se envolvam em atividades esportivas, religiosas e comunitárias. Entre os aspectos relacionados à cultura, recebem destaque a identidade étnica positiva, a identificação com crenças e valores culturais e a socialização entre grupos de pares. Com relação à família, os autores assinalam a competência e o estilo parental, a presença de adulto como apoio social, a ausência de traumas, separações ou perdas em idade precoce, a coesão familiar e o nível de escolaridade dos pais. Nesse sentido, vários estudos têm chamado a atenção para a importância da dinâmica familiar e das práticas e atitudes parentais, não somente como fator protetivo e promotor da resiliência, mas como um dos elementos fundamentais para o desenvolvimento do talento (Chagas, 2008; Chagas \& Fleith, 2009; Dessen, 2007).

\section{Considerações finais}

Os resultados evidenciados em nosso estudo nos levam a inferir a importância dos processos avaliativos e de mapeamento de talentos, uma vez que o tipo de talento modifica o conjunto de características individuais, habilidades, interesses e estilos de aprendizagem, com isso ensejando múltiplos procedimentos de acesso a programas por meio de estratégias diversificadas de avaliação, intervenção e atendimento.

Ainda com relação aos aspectos acadêmicos, enfatizamos o papel relevante da mediação de mentores no desenvolvimento do talento, da participação na sala de recursos e em eventos como mostras, exposições, feiras, 
lançamento de livros e concursos. Entre os adolescentes que participaram da pesquisa, $80 \%$ indicaram ter recebido influência de um mentor ou professor e mais da metade declarou ter recebido algum tipo de prêmio em concursos. Além disso, a participação na sala de recursos foi indicada como uma das experiências mais marcantes na promoção do desenvolvimento do talento. A sala de recursos foi o único microssistema onde $100 \%$ dos adolescentes informaram se sentir aceitos e integrados, fato que ressalta a importância de atendimento adequado e especializado ao adolescente talentoso e o seu envolvimento em eventos socioculturais (Fleith, 2007; Virgolim, 2007).

A partir dos resultados deste estudo emerge, também, a necessidade de serem amplamente planejadas e empregadas atividades que visem ao desenvolvimento de habilidades sociais nas escolas, principalmente, nos programas que atendem adolescentes talentosos. Várias atividades devem ser planejadas de forma sistemática tendo em vista auxiliar: (a) no fortalecimento e na construção de autoimagem, autoestima e autoconceito positivos, (b) na construção de uma identidade integrada, (c) na elaboração de estratégias não-violentas de enfrentamento do bullying e (d) na manutenção de relacionamento interpessoal positivo, sem, no entanto, abrirem mão de suas habilidades e interesses ou mesmo virem a negar o talento.

Destacamos, ainda com base nos resultados desta pesquisa, algumas implicações para pesquisas futuras: o planejamento de pesquisas longitudinais e transversais para maior detalhamento das características evolutivas do desenvolvimento do talento ao longo do ciclo de vida, estudos que enfoquem as interconexões com relação às diferenças de gênero, tipos de talentos e estabilidades e mudanças ao longo do tempo. Igualmente, seria necessário investigar de forma mais acurada os efeitos do bullying sobre o ajustamento socioemocional e a construção da identidade de adolescentes talentosos, bem como a confluência das características individuais, familiares e sócio-histórico-culturais no desenvolvimento do talento e de comportamentos de resiliência.

Entre as limitações do estudo destacamos a pequena amostra de alunos com duplo talento quando comparados aos alunos com talentos na área de artes ou na área acadêmica. Com relação à seleção de participantes, não foi possível adoção de técnicas de amostragem randômica, restringindo a generalização dos resultados. Outra limitação é o fato dos instrumentos não terem sido aplicados exclusivamente pela pesquisadora, mas em sua maioria pelos professores e psicólogos do programa. Essa estratégia pode ter comprometido a padronização do processo de coleta de dados, influenciando na maneira como o respondente elaborou a sua resposta ao instrumento. Com o objetivo de minimizar o impacto desses fatores no processo de coleta de dados, foi elaborado documento contendo orientações de preenchimento do instrumento e o passo a passo do procedimento a ser adotado.

\section{Referências}

Alencar, E. M. L. S. (2007). Indivíduos com altas habilidades/superdotação: clarificando conceitos, desfazendo idéias errôneas. Em D. S. Fleith (Org.). A construção de práticas educacionais para alunos com altas habilidades/superdotação. Orientação a professores (pp. 16-23). Brasília: MEC/SEESP.

Bianculli, C. H. (1997). Realidad y propuestas para continencia de la transición adolescente en nuestro medio. Adolescencia Latinoamericana, 1, 31-39.

Chagas, J. F. (2007). Conceituação e fatores individuais, familiares e culturais relacionados às altas habilidades. Em D. S. Fleith \& E. M. L. S. Alencar (Orgs.). Desenvolvimento de talentos $e$ altas habilidades (pp. 15-24). Porto Alegre: Artmed.

Chagas, J. F. (2008). Adolescentes talentosos. Tese de Doutorado, Universidade de Brasília, BrasíliaDF.

Chagas, J. F. \& Fleith, D. S. (2009). Estudo comparativo sobre superdotação com famílias em situação sócio-econômica desfavorecida. Revista Brasileira de Educação Especial, 15, 155 170.

Chen, J., Isberg, E. \& Krechevsky, M. (2001). Atividades iniciais de aprendizagem. Em H. Gardner, D. H. Feldman \& M. Krechevsky (Orgs.). Projeto spectrum: a teoria das inteligências múltiplas na educação infantil (Vol. 2). Porto Alegre: Artmed.

Costa, I. E. R., Ludemir, A. B. \& Avelar, I. (2007). Violência contra adolescentes: diferenciais segundo estratos de condição de vida e sexo. Ciência e Saúde Coletiva, 12, 1193-1200. 
Csikszentmihalyi, M., Rathunde, K. \& Whalen, S. (1993). Talented teenagers: the roots of success \& failure. Nova Iorque: Cambridge University Press.

Dessen, M. A. (2007). A família como contexto de desenvolvimento. Em D. S. Fleith (Org.). A construção de práticas educacionais para alunos com altas habilidades/ superdotação. O aluno e a família (pp. 13-28). Brasília: MEC/SEESP.

Edmunds, A. L. \& Edmunds, G. A. (2005). Sensitivity: a double-edged sword for the preadolescent and adolescent gifted child. Roeper Review, 27, 69-77.

Fleith, D. S. (2007). A construção de práticas educacionais para alunos com altas habilidades/superdotação (Vol. 2-4). Brasília: MEC/SEESP.

Fortes-Lustosa A. V. (2004). Moral em superdotados: uma nova perspectiva. Tese de Doutorado, Universidade de Brasília, Brasília-DF.

Fortes-Lustosa A. V. (2007). Desenvolvimento moral do aluno com altas habilidades. Em D. S. Fleith \& E. M. L. S. Alencar (Orgs.). Desenvolvimento de talentos $e$ altas habilidades (pp. 67-78). Porto Alegre: Artmed.

Gardner, H. (2001). Inteligência: um conceito reformulado. Rio de Janeiro: Objetiva.

Grobman, J. (2006). Underachievement in exceptionally gifted adolescents and young adults: a psychiatric's view. The Journal of Secondary Gifted Education, 17, 199-210.

Günther, H. (2006). Pesquisa qualitativa versus pesquisa quantitativa: esta é a questão? Psicologia: Teoria e Pesquisa, 22, 201-210.

Hutz, C. S. (2002). Situações de risco e vulnerabilidade na infância e adolescência: aspectos teóricos e estratégias de intervenção. São Paulo: Casa do Psicólogo.

Jackson, P. S. \& Peterson, J. S. (2003). Depressive disorder in highly gifted students. Journal of Secondary Gifted Education, 14, 175-186.

Kotliarenco, M. A., Cáceres, I. \& Fontecilla, M. (1997). Estado de arte en resiliencia. Washington, DC: Organización Panamericana de la Salud \& Organización Mundial de la Salud.

Molina-Loza, C. A. (2003). Resiliência: um olhar diferente sobre a tragédia humana. Trabalho apresentado na VI Conferência Internacional de Filosofia, Psiquiatria e Psicologia, Brasília,
DF.

Neihart, M. (1999). The impact of giftedness on psychological well-being: what does the empirical literature say? Roeper Review, 22, 1018.

Neihart, M. (2002). Gifted children and depression. Em M. Neihart, S. M. Reis, N. M. Robinson \& S. M. Moon (Orgs.). The social and emotional development of gifted children: what do we know? (pp. 93-102). Washington, DC: Prufock Press.

Neihart, M. (2006). Achievement/affiliation conflicts in gifted adolescents. Roeper Review, 28, 196-202.

Ourofino, V. T. A. T. \& Guimarães, T. G. (2007). Características intelectuais, emocionais e sociais do aluno com altas habilidades/superdotação. Em D. S. Fleith (Org.). A construção de práticas educacionais para alunos com altas habilidades/superdotação. Orientação a professores (pp. 41-52). Brasília: SEESP.

Peterson, J. S. \& Ray, K. E. (2006). Bullying among the gifted: the subjective experience. Gifted Child Quaterly, 50, 252-269.

Renzulli, J. S. \& Reis, S. M. (1997). The Schoolwide Enrichment Model: a how-to guide for educational excellence (2a . ed.). Mansfield Center, CT: Creative Learning Press.

Renzulli, J. S. \& Smith, L. H. (2001). Learning Styles Inventory. Mansfield, Center, CT: Creative Learning Press.

Renzulli, J. S., Smith, L. H., White, A. J., Callahan, C. M., Hartman, R. K. \& Westberg, K. L. (2000). Scales for rating the behavior characteristics of superior students. Revised edition (SRBCSS-R). Mansfield Center, CT: Creative Learning Press.

Richards, J., Encel, J. \& Shute, R. (2003). The emotional and behavioural adjustment of intellectually gifted adolescents: a multidimensional, multi-informant approach. High Ability Studies, 14, 153-164.

Sabatella, M. L. P. (2008). Talento e superdotação: problema ou solução? Curitiba: IBPEX.

Schuler, P. (2002). Perfectionism in gifted children and adolescents. Em M. Neihart, S. M. Reis, N. M. Robinson \& S. M. Moon (Orgs.). The social and emotional development of gifted children: 
what do we know? (pp. 71-79). Washington, DC: Prufock Press.

Schultz, R. A. \& Deslile, J. R. (2003). Gifted adolescents. Em N. Colangelo \& G. A. Davis (Orgs.). Handbook of gifted education (pp. 483492). London: Pearson Education.

UNICEF (2002a). Relatório sobre a situação da adolescência no Brasil. Brasília: UNICEF.

UNICEF. (2002b). A voz do adolescente. Brasília: UNICEF.

Virgolim, A. M. R. (2007). Altas habilidades/superdotação: encorajando potenciais. Brasília: MEC/SEESP.

Waller, M. A. (2001). Resilience in ecosystemic context: evolution of the concept. American Journal of Orthopsychiatry, 7, 1-8.

Winner, E. (1998). Crianças superdotadas: mitos e realidades. Porto Alegre: Artes Médicas.

Recebido em agosto de 2009 Reformulado em novembro de 2009 Aprovado em fevereiro de 2010

Sobre as autoras:

Jane Farias Chagas é licenciada em Música, bacharel em Teologia, psicopedagoga, mestre em Psicologia e doutora em Processos de Desenvolvimento Humano e Saúde. Foi coordenadora da Unidade de Apoio aos Professores do Núcleo de Altas Habilidades/Superdotação - NAAHS/DF e atualmente é consultora junto à UNESCO/Secretaria Extraordinária de Educação Integral do DF e docente no ensino superior e na pósgraduação.

Denise de Souza Fleith é psicóloga, Ph.D. pela University of Connecticut e professora associada do Instituto de Psicologia da Universidade de Brasília. Realizou seu pós-doutorado na National Academy for Gifted and Talented Youth na University of Warwick, Inglaterra. É pesquisadora do Conselho Nacional de Desenvolvimento Científico e Tecnológico e representa o Brasil no Conselho Mundial para Crianças Superdotadas e Talentosas. 